\title{
Study of a Low-Cost PV Emulator for Testing MPPT Algorithm Under Fast Irradiation and Temperature Change
}

\author{
A. Chalh ${ }^{1}$ (D) S. Motahhir ${ }^{1}$ - A. El Hammoumi ${ }^{1}$ - A. El Ghzizal ${ }^{1}$ - A. Derouich ${ }^{1}$ \\ Received: 8 February 2018 / Accepted: 3 June 2018 / Published online: 16 August 2018 \\ (C) Springer Nature Singapore Pte Ltd. 2018
}

\begin{abstract}
This paper presents a study of a low-cost photovoltaic (PV) emulator to test the real implementation of maximum power point tracking (MPPT) algorithm. This PV emulator is composed of a variable DC supply in series with a variable resistor; it is based on the maximum power transfer theorem in order to provide a curve that exhibits a peak which can be tracked by an MPPT algorithm. Moreover, this emulator can be used to test the performance of the MPPT algorithm under fast variation of the solar irradiance and temperature. For this reason, the P\&O MPPT algorithm with a boost DC-DC converter is used in order to validate the functionality of the PV emulator. Finally, the experimental results show that our PV emulator can provide a simple, efficient and low-cost way for users (researchers, engineers, students, etc.) to test and validate their MPPT algorithms.
\end{abstract}

Keywords DC supply · Low cost · PV emulator · MPPT · Photovoltaic

\section{Introduction}

Today, solar energy has taken a large part of the market due to the continued development of PV system technology and its lower prices [1]. Therefore, several reseachers are working on the optimization of this source of energy in order to extract power with high reliability, low cost, and improve energy efficiency [2].

The energy production of PV panels is dramatically affected by climatic conditions in terms of solar irradiance and temperature [3, 4]. Besides, the power provided by the PV panels is maximum only when the latter operates at its maximum power point (MPP). Therefore, the MPPT controller is used to track the MPP. In this context, a large number of MPPT methods have been developed in the literature, such as: Perturb \& Observe (P\&O) [5, 6], incremental conductance (INC) [7-9], fractional open

\footnotetext{
A. Chalh

abdelilah.chalh@usmba.ac.ma

1 Laboratory of Production Engineering, Energy and Sustainable Development, Smart Energy Systems and Information Processing Research Team, Higher School of Technology, SMBA University, Fez, Morocco
}

circuit voltage [10], fractional short-circuit current [5], fuzzy logic control [11], and neural network [12], etc.

On the other hand, to validate the performance of such MPPT algorithm, it is required to test it under different values of temperature and irradiance. However, it is difficult to realize the desired test case because we cannot control the climatic conditions [13].

Therefore, different solutions have been used in the literature that can be classified into two categories: commercial ones and proposed ones in science research. Among the most used commercial solutions, we find:

- Artificial lights [14, 15].

- The Agilent Solar Simulator [16].

- PV emulators based on DC power programmable [17, $18]$.

Firstly, the solution presented in $[14,15]$ is based on using spotlights served as a light source to produce the light on the PV panel surface. Then by controlling the light intensity, it is possible to make the desired test case to emulate the irradiance change. But, the inconvenient of this solution is that the spotlights increase dramatically the PV panel temperature. Moreover, several PV emulators commercial have been used in [16-18], they are considered as the best devices to emulate the P-V and I-V curves of the PV panel under desired climatic conditions. However, these solutions 
are very expensive and not always available in all research laboratories.

On another hand, many solutions have been proposed in the literature especially the following ones:

- PV emulator based on DC power supply and DCDC buck-boost DC/DC converter controlled by microcontroller [19].

- PV emulator based on DC power supply and PV panel [20].

- PV emulator based on DC power supply and series resistor [21].

The PV emulator presented in [19] is based on a DC power supply and a buck-boost DC/DC converter which is controlled by a microcontroller. This $\mathrm{PV}$ emulator is complex and expensive because of using several devices to build it such as buck-boost and its components and the microcontroller. Secondly, work proposed in [20] presents a $\mathrm{PV}$ emulator that is constructed by the parallel connection of PV panel and a DC power supply. This PV emulator can simulate a variety of I-V curves under different solar irradiations, but it is not giving the way to emulate the temperature variation. Thus, a low-cost PV emulator is proposed in [21] which is based on a variable voltage analog DC power supply with a resistor. Nevertheless, this PV emulator was not well investigated.

For that, this work aims to study a low-cost PV emulator to provide a simple and low-cost way to test the real implementation of MPPT algorithms. This PV emulator is composed of a variable DC supply in series with a variable resistor.

This paper is organized as follows. The next section presents operating configuration which describes: maximum power transfer theorem, sizing of PV emulator, and PV emulator for testing the fast variation of Solar irradiance and temperature. Next, the Experimental and validation are presented in "Experimental and Validation". And the conclusion is given in "Conclusion".

\section{Operating Configuration}

\section{Maximum Power Transfer Theorem}

PV emulator must give a power curve as this of PV panel that exhibits a peak. Therefore, a simple DC supply in series with a variable resistor can be used, because based on 'maximum power transfer theorem' this DC supply can provide its maximum power when load resistor equals to the series resistor. The PV emulator basic schematic is presented in Fig. 1.

The 'maximum power transfer theorem' can be explained as follows [22]:

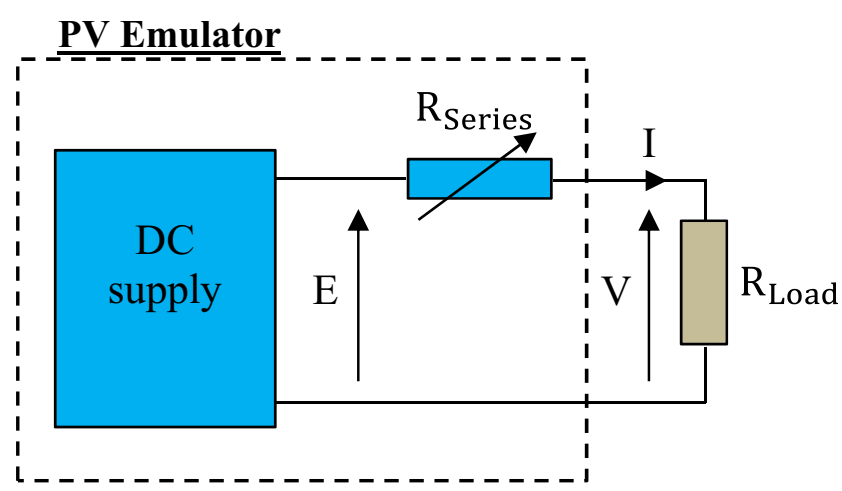

Fig. 1 Basic schematic of the PV emulator

Based on Fig. 1, the following equations can be found:

$P_{\text {load }}=I * V=I^{2} * R_{\text {load }}$

$I=\frac{E}{R_{\text {series }}+R_{\text {load }}}$

Replacing Eq. 2 in Eq. 1, Eq. 3 is found:

$P_{\text {load }}=\frac{R_{\text {load }}}{\left(R_{\text {series }}+R_{\text {load }}\right)^{2}} * E^{2}$

$\frac{d P_{\text {load }}}{d R_{\text {Load }}}=E^{2} \frac{R_{\text {series }}-R_{\text {load }}}{\left(R_{\text {series }}+R_{\text {load }}\right)^{3}}$

The power is at its maximum when its derivative is equal to zero. Then from Eq. 4, this can be reached when the load resistor is equal to the series resistor as follows:

$R_{\text {load }}=R_{\text {series }}$

Therefore, in this case, maximum power transfer condition (5) will appear when the voltage of the load is half of that generated by the DC supply.

$V=\frac{E}{2}$

\section{Sizing of the PV Emulator}

As described previously, the PV emulator must reflect the behavior of the PV panel and especially in the P-V curve at MPP. Table 1 presents the characteristics of the PV panel used in this work.

In order to size the PV emulator parameters (The value of DC supply and the series resistor), the values of DC supply (E) and the series resistor can be calculated by the following equations:

$R_{\text {serie }}=R_{m p p}=\frac{V_{m p p}}{I_{m p p}}$

$E=2 * V_{m p p}$

From Table 1, and Eqs. 7 and 8, the values of DC supply and series resistor at STC are respectively $37.52 \mathrm{~V}$ and $17.53 \Omega$. 
Table 1 Characteristics of the PV panel TDC-M20-36 at STC

\begin{tabular}{ll}
\hline Characteristics TDC-M20-36 & \\
\hline Maximum power, Pmax & $20 \mathrm{~W}$ \\
Voltage at Pmax, Vmp & $18.76 \mathrm{~V}$ \\
Current at Pmax, Imp & $1.07 \mathrm{~A}$ \\
Short-circuit current, Isc & $1.17 \mathrm{~A}$ \\
Open-circuit voltage, Voc & $22.70 \mathrm{~V}$ \\
Temperature coefficient of Voc, Kv & $-0.35 \% /{ }^{\circ} \mathrm{C}$ \\
Temperature coefficient of Isc, $\mathrm{Ki}$ & $-0.043 \% /{ }^{\circ} \mathrm{C}$ \\
Number of cells & 36 \\
\hline
\end{tabular}

Generally, only one resistor value can lead the PV panel to operate at its MPP [23]. Figure 2 shows a complete schematic view of the PV emulator control. The PV panel is replaced by DC supply and series resistor. So, the MPPT bloc is constituted by the DC-DC converter controlled by an MPPT algorithm in order to operate the PV emulator at MPP, when the equivalent resistor (between PV emulator and load) is equal to the value of the series resistor.

\section{PV Emulator for Testing the Fast Variation of Solar Irradiance and Temperature}

MPPT algorithms must be tested for different solar irradiance and temperature values to validate its robustness.

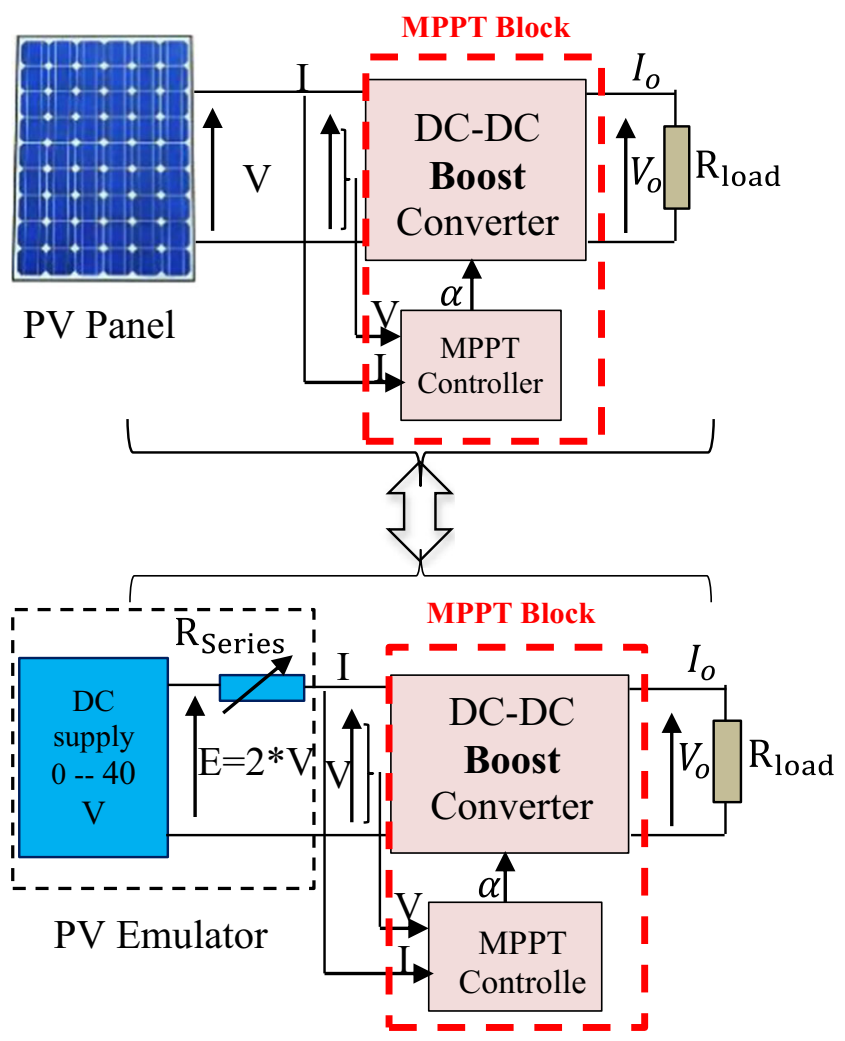

Fig. 2 A complete schematic of the PV emulator system

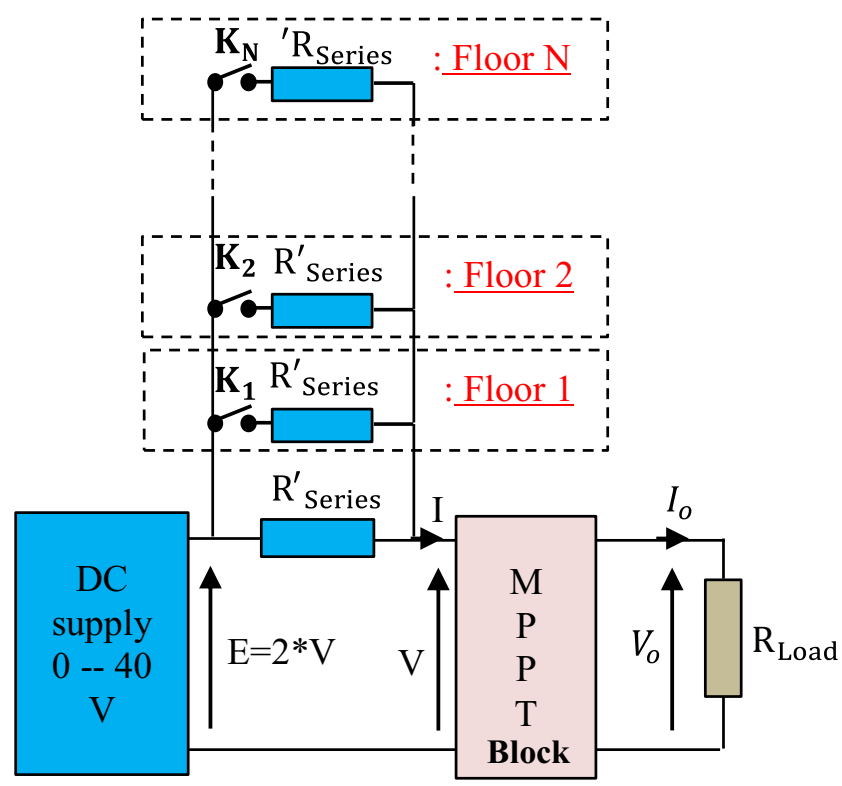

Fig. 3 General design to emulate of the fast variation of the solar irradiance

But as was described previously that is difficult to make such tests in reality. For this reason, a study to emulate several values of these parameters is described in this part.

- Fast variation of the solar irradiance

A simple design based on the PV emulator is developed to emulate different values of the solar irradiance and it is presented in Fig. 3. The number of solar irradiance values depends on the number of floors. To emulate a number $\mathrm{N}$ of values of solar irradiance we must add N-1 of floors. Then the value of $R_{\text {series }}$ can be calculated by the following equation:

$R_{\text {series }}^{\prime}=N \times R_{\text {series }}$

For instance, to emulate five values of solar irradiance, four floors must be used, for that $R_{\text {series }}^{\prime}$ is equal to $5 \times R_{\text {series }}$. In Table 2, the solar irradiance values which can be obtained by using 4 floors with 5 combination of the switches are

Table 2 Obtained solar irradiance values according to the switches states by using four floors

\begin{tabular}{lllll}
\hline & $\mathrm{K} 1$ & $\mathrm{~K} 2$ & $\mathrm{~K} 3$ & $\mathrm{~K} 4$ \\
\hline $\mathrm{G}=1000 \mathrm{~W} / \mathrm{m}^{2}$ & 1 & 1 & 1 & 1 \\
$\mathrm{G}=800 \mathrm{~W} / \mathrm{m}^{2}$ & 1 & 1 & 1 & 0 \\
$\mathrm{G}=600 \mathrm{~W} / \mathrm{m}^{2}$ & 1 & 1 & 0 & 0 \\
$\mathrm{G}=400 \mathrm{~W} / \mathrm{m}^{2}$ & 1 & 0 & 0 & 0 \\
$\mathrm{G}=200 \mathrm{~W} / \mathrm{m}^{2}$ & 0 & 0 & 0 & 0 \\
\hline
\end{tabular}




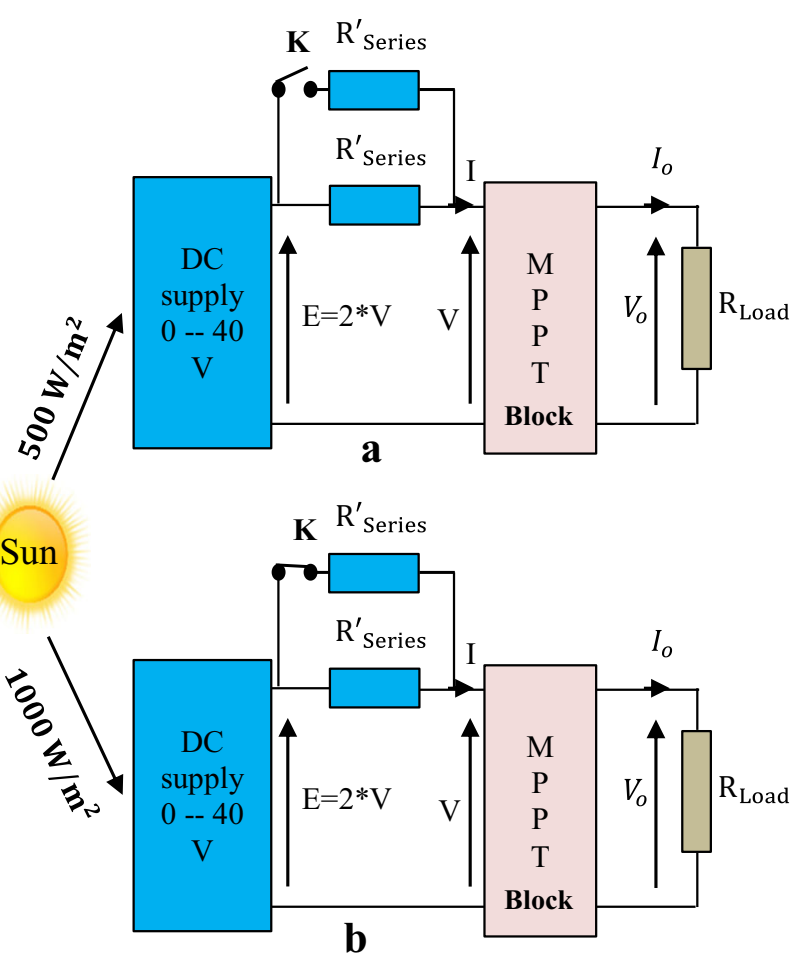

Fig. 4 Example of the fast variation of the solar irradiance

presented. Generally, obtained solar irradiance values can be calculated by using the following equation:

$G=\frac{(K+1) \times 1000}{N}$

Where $\mathrm{G}$ the value of the solar irradiance level and $\mathrm{K}$ is the number of closed switches.

For enriching understanding, an example of a rapid change of the solar irradiance from $500 \mathrm{~W} / \mathrm{m}^{2}$ to $1000 \mathrm{~W} / \mathrm{m}^{2}$ is developed in Fig. 4. In the case of $500 \mathrm{~W} / \mathrm{m}^{2}$ of the

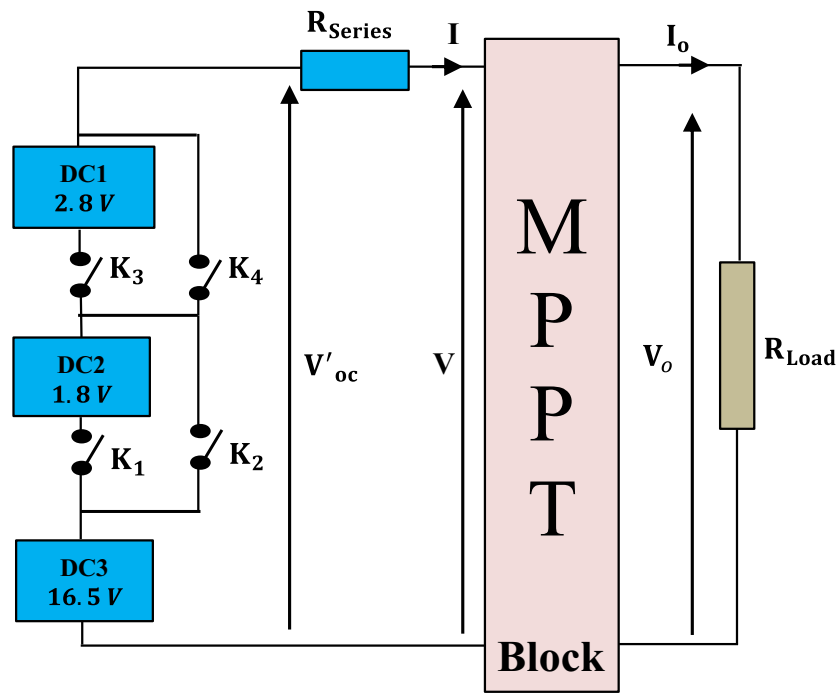

Fig. 5 Example of the fast variation of the solar irradiance
Table 3 Different temperature values according to the switches states

\begin{tabular}{lllll}
\hline & $\mathrm{K} 1$ & $\mathrm{~K} 2$ & $\mathrm{~K} 3$ & $\mathrm{~K} 4$ \\
\hline $\mathrm{T} 3\left(\mathrm{~V}_{\mathrm{oc}}^{\prime}=16.5 V\right)$ & 0 & 1 & 0 & 1 \\
$\mathrm{~T} 2\left(\mathrm{~V}_{\mathrm{oc}}^{\prime}=18.3 V\right)$ & 1 & 0 & 0 & 1 \\
$\mathrm{~T} 1\left(\mathrm{~V}_{\mathrm{oc}}^{\prime}=21.1 V\right)$ & 1 & 0 & 1 & 0 \\
\hline
\end{tabular}

solar irradiance (Fig. 4a), the switch K1 must be opened so that the value of the equivalent resistor is equal to 35.16 $\Omega\left(\mathbf{2} \times \mathbf{R}_{\text {series }}\right)$. And if we close the switch K1 (Fig. $\left.4 \mathrm{~b}\right)$, the value of the equivalent resistor will be equal to 17.53 $\Omega$ which correspond to $R_{\text {series. }}$. In this case, the value of the solar irradiance occurs $1000 \mathrm{~W} / \mathrm{m}^{2}$. Then to emulate the fast change of the solar irradiance of $500 \mathrm{~W} / \mathrm{m}^{2}$ to $1000 \mathrm{~W} / \mathrm{m}^{2}$ it is necessary to permute the state of the switch $\mathrm{K} 1$ from 0 to 1 .

- Fast variation of temperature

Figure 5 describes a simple method to emulate 3 values of temperature. The idea is that by replacing the DC supply of PV emulator by 3 DC supply in series so that the sum of their voltages must be equal to the desired maximum value of $\mathrm{V}_{\mathrm{oc}}^{\prime}$. This value corresponds to the desired minimum temperature value. If we want to emulate at least a temperature of $25^{\circ} \mathrm{C}$, which corresponds to the MPP at STC, the $\mathrm{V}_{\mathrm{oc}}^{\prime}$ must be equal to $2 \times \mathrm{V}_{\mathrm{mpp}}$. In Table 3, the temperature values (with $\mathrm{T} 1<\mathrm{T} 2<\mathrm{T} 3$ ) which can be obtained by using $3 \mathrm{DC}$ supply with four switches are presented. Then to emulate a fast change of the temperature it is necessary to permute the state of the switches as shown in Table 3.

\section{Experimental and Validation}

\section{PV Emulator Validation}

The circuit model and the experimental setup of the developed system are presented in Figs. 6 and 7 respectively in order to validate the performance of used PV emulator.

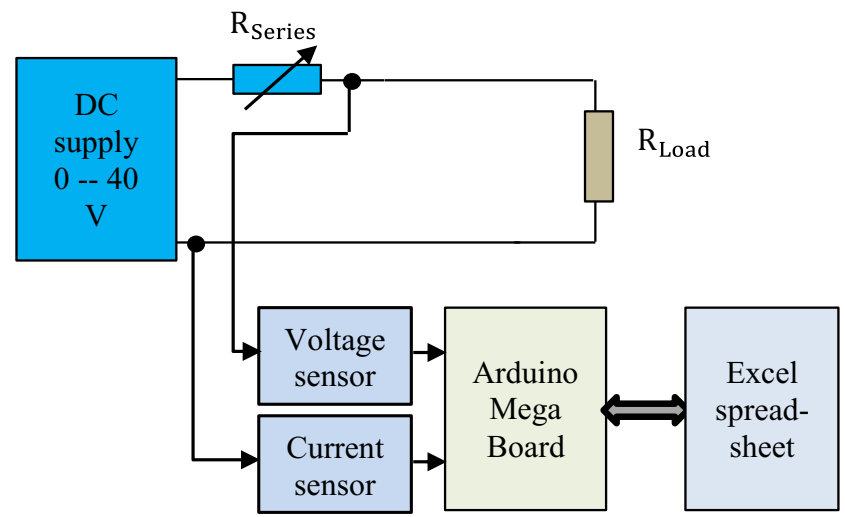

Fig. 6 Circuit model of the developed PV emulator 


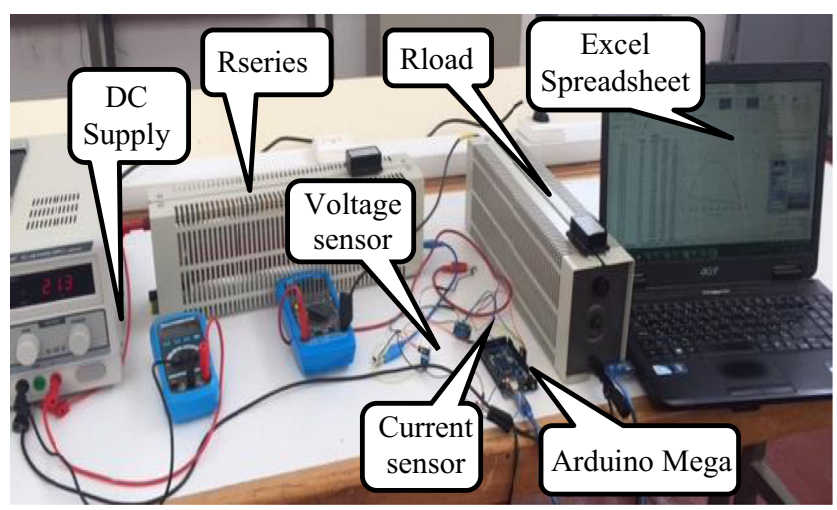

Fig. 7 Experimental setup of used PV emulator system

The output power obtained by voltage and current sensors is transmitted and plotted directly in real-time in Excel by using PLX-DAQ data acquisition Macro, which allows communication between the microcontroller of the Arduino Mega and an Excel spreadsheet through serial communication [24]. Figure 8 presents the experiment P-V and I-V curves characteristics of the PV emulator. As shown in Fig. 8, the peak in the power curve occurs when the output voltage of the PV emulator is half of the Dc power supply voltage.

\section{Effect of the Solar Irradiance Variation}

Figure 9 presents the experimental P-V curves for a fixed $\mathrm{V}_{\mathrm{oc}}^{\prime}$ and various series resistances. This situation is similar to variation of the solar irradiance in case of PV panel.

Figure 10 shows the experimental I-V curves for different series resistors at fixed $\mathrm{V}_{\mathrm{oc}}^{\prime}$. According to this figure, the short-circuit current of PV emulator decreases when the value of $R_{\text {series }}$ increases. It is noticed that when the series resistor varies in the PV emulator, the current varies linearly and do not reflect the actual I-V characteristic of a PV panel. Nevertheless, we are interested in the $\mathrm{P}-\mathrm{V}$ characteristic which presents a peak in the power

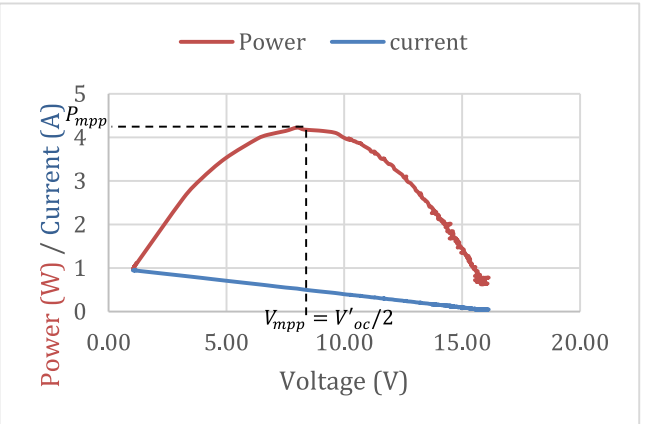

Fig. 8 Experimental P-V and I-V curves characteristics of the PV emulator curve that can be followed by the MPPT algorithm to be tested.

\section{Effect of Temperature Variation}

Figure 11 presents the experimental P-V curves for a fixed $\boldsymbol{R}_{\text {series }}$ and various value of the $\mathrm{V}_{\mathrm{oc}}^{\prime}$. This situation similar to changing temperature conditions in PV panel.

Consequently, we can simulate the effects of the solar irradiance and temperature variations by varying, respectively, the value of the series resistor and the voltage of the DC supply.

\section{Implementation of MPPT Algorithm Using the PV Emulator}

\section{MPPT Algorithm}

In order to verify the ability of used PV emulator to test the real implementation of an MPPT algorithm, the P\&O MPPT algorithm is used as an example in this work. $\mathrm{P} \& \mathrm{O}$ MPPT is a popular control method for PV applications due to its simplicity. The principle operation of the $\mathrm{P} \& \mathrm{O}$ MPPT algorithm is based on the factor $\frac{\mathrm{dP}}{\mathrm{dV}}$ at the P-V curves. Figure 12 shows the three variation cases of the MPP according to $\frac{\mathrm{dP}}{\mathrm{dV}}$ factor: $1\left(\frac{\mathrm{dP}}{\mathrm{dV}}>0\right), 2\left(\frac{\mathrm{dP}}{\mathrm{dV}}=0\right)$ and 3 $\left(\frac{\mathrm{dP}}{\mathrm{dV}}<0\right)$. The advantages of this method are its simple structure, less requirement of parameter measurements, and the possibility of its implementation in a low-cost microcontroller. Therefore, the $\mathrm{P} \& \mathrm{O}$ MPPT algorithm is used to validate the good performance of used PV emulator.

The flowchart of the implemented P\&O MPPT algorithm is shown in Fig. 13.

\section{The Boost Converter Construction and Parameters}

The DC-DC boost converter is inserted between the PV panel and the load. This converter generates an output voltage and current from the current and voltage of the input and the duty cycle $\alpha$. This duty cycle is calculated by the MPPT algorithm and varies between 0 and 1 . The figure below shows the circuit of the DC-DC boost converter [8] (Fig. 14).

The equations of this DC-DC converter are shown below:

$\mathrm{V}_{\mathrm{o}}=\frac{\mathrm{V}}{1-\alpha}$

$\mathrm{I}_{0}=\mathrm{I}(1-\alpha)$

Where $\alpha$ is the duty cycle, $\mathrm{V}$ is the converter input voltage, I is the input current of the Boost converter, $V_{\mathrm{o}}$ is the output voltage and $\mathrm{I}_{\mathrm{O}}$ is the output current of the Boost converter. 
Fig. 9 Experimental P-V curves for many series resistance at fixed $V_{\mathrm{oc}}^{\prime}$

Fig. 10 Experimental I-V curves for different series resistance at fixed $\mathrm{V}_{\mathrm{oc}}^{\prime}$

Fig. 11 Experimental P-V curves for different $\boldsymbol{V}_{\boldsymbol{o c}}^{\prime}$ at fixed $\boldsymbol{R}_{\text {series }}$
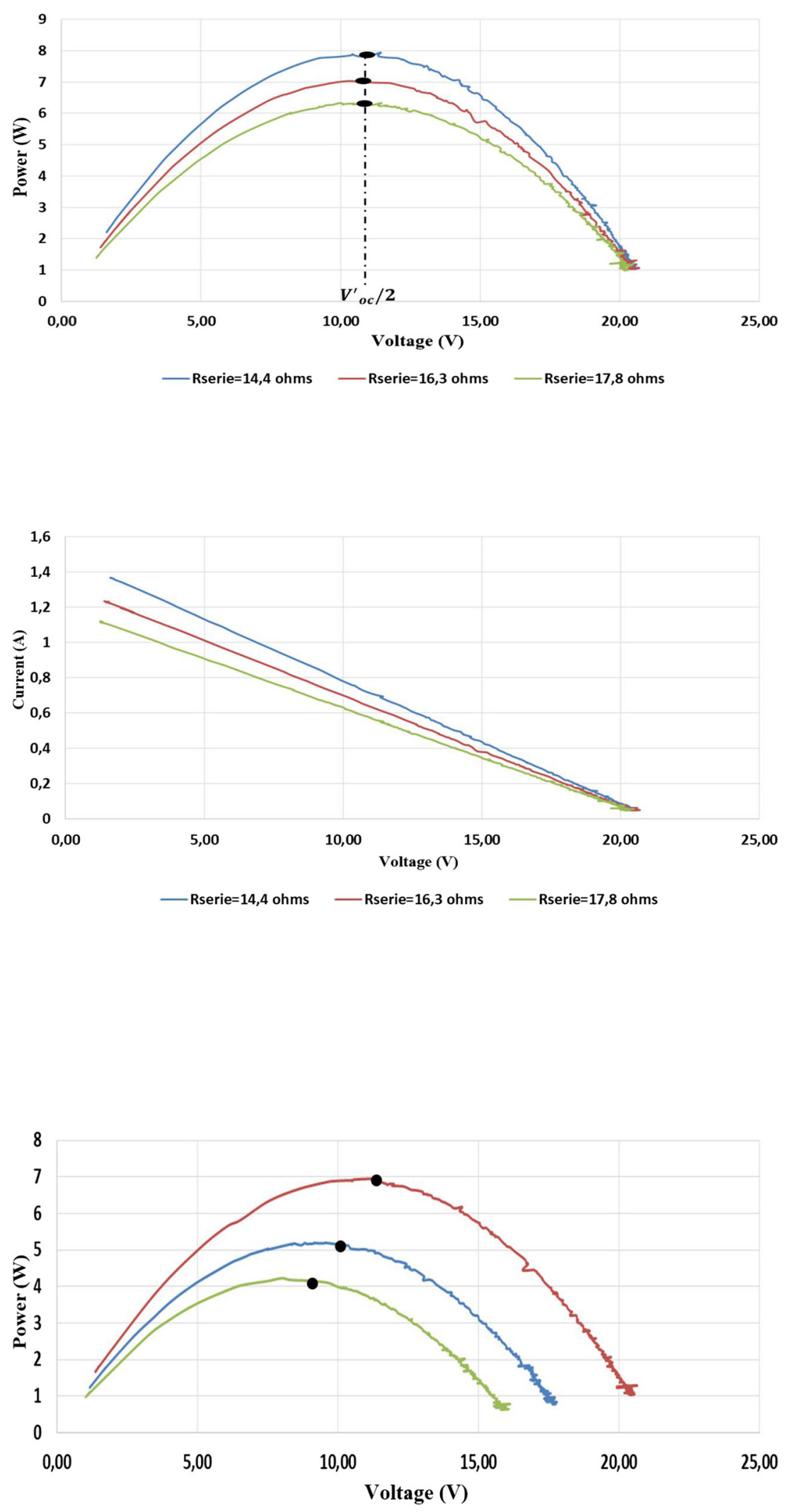

-P For Voc $=21,1 \mathrm{~V} \longrightarrow \mathrm{P}$ For Voc $=18,3 \mathrm{~V}-\mathrm{P}$ For Voc $=16,5 \mathrm{~V}$ 
Fig. 12 Slope $\left(\frac{d \mathbf{P}}{d V}\right)$ variation operation of $\mathrm{P} \& \mathrm{O}$ MPPT and steady state three level

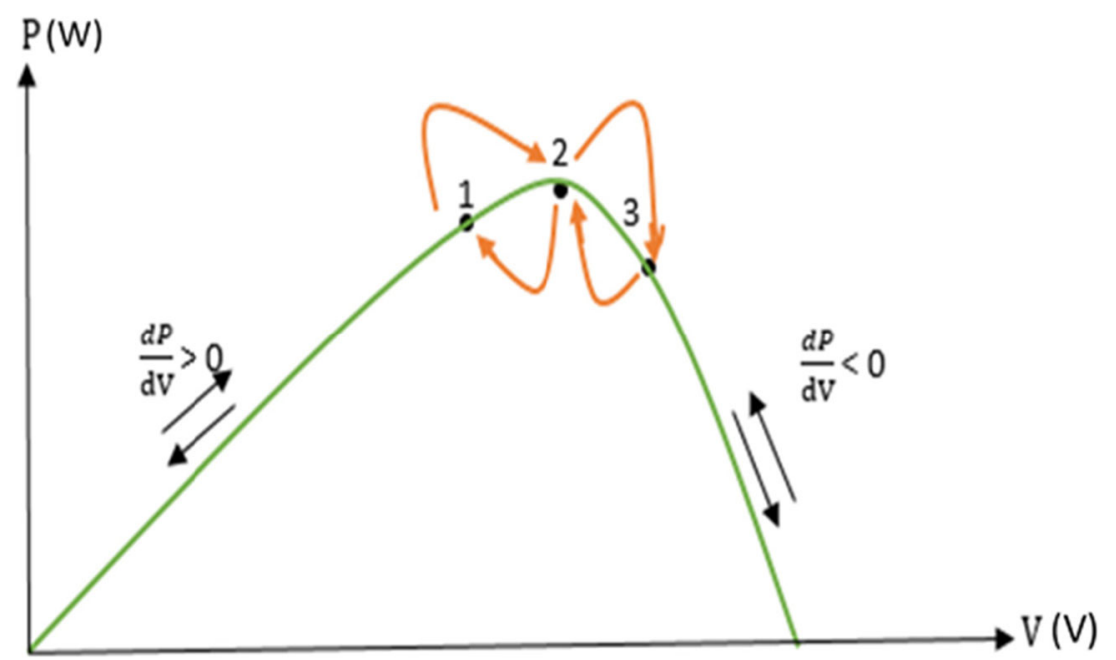

Fig. 13 The flowchart of the implemented P\&O MPPT algorithm

Fig. 14 DC-DC boost converter

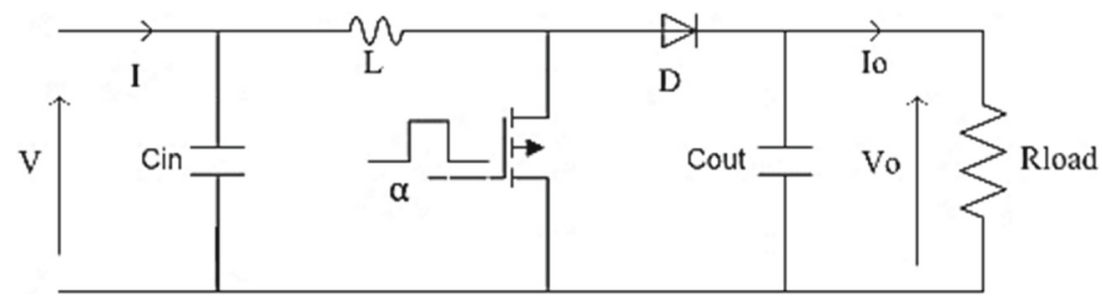


Table 4 Parameters of the boost DC/DC converter

\begin{tabular}{lc}
\hline Parameters of the boost DC/DC converter \\
\hline Inductor $(\mathbf{L})$ & $20 \mathrm{mH}$ \\
Input capacitor $\left(\boldsymbol{C}_{\boldsymbol{i n}}\right)$ & $220 \mu \mathrm{F}$ \\
Output capacitor $\left(\boldsymbol{C}_{\text {out }}\right)$ & $470 \mu \mathrm{F}$ \\
Switching frequency & $1 \mathrm{kHz}$ \\
\hline
\end{tabular}

The parameters of the elements used in the boost DC/DC converter are given in Table 4.

\section{Test Results}

Figure 15 present the experimental setup assembled in the laboratory. The setup consists of used PV emulator, the DC-DC boost converter, load, Arduino Mega board, and a computer to display the experimental results in real-time in Excel. The P\&O MPPT algorithm is implemented by the boost converter control with a frequency of $1 \mathrm{kHz}$.

To validate the functionality and performance of used PV emulator, the P\&O MPPT algorithm is tested with a fast change in solar irradiance. At first, the solar irradiance is suddenly decreased by applying a step from $1000 \mathrm{~W} / \mathrm{m}^{2}$ to $500 \mathrm{~W} / \mathrm{m}^{2}$ at $\mathrm{t}=1 \mathrm{~s}$, then it is increased by applying a step from $500 \mathrm{~W} / \mathrm{m} 2$ to $750 \mathrm{~W} / \mathrm{m}^{2}$ at $\mathrm{t}=2 \mathrm{~s}$. The test result is presented in Fig. 16. As shown in Fig. 16, it can be observed that the powers correspond to MPP for the above-mentioned solar irradiance conditions are respectively $20 \mathrm{~W}, 10 \mathrm{~W}$, and $15 \mathrm{~W}$.

In addition, Fig. 17 present the test result for two steps increase in temperature level, from $\mathrm{T} 1$ to $\mathrm{T} 2$ at $\mathrm{t}=1 \mathrm{~s}$ and from $\mathrm{T} 2$ to $\mathrm{T} 3$ at $\mathrm{t}=2 \mathrm{~s}$. It can be observed from

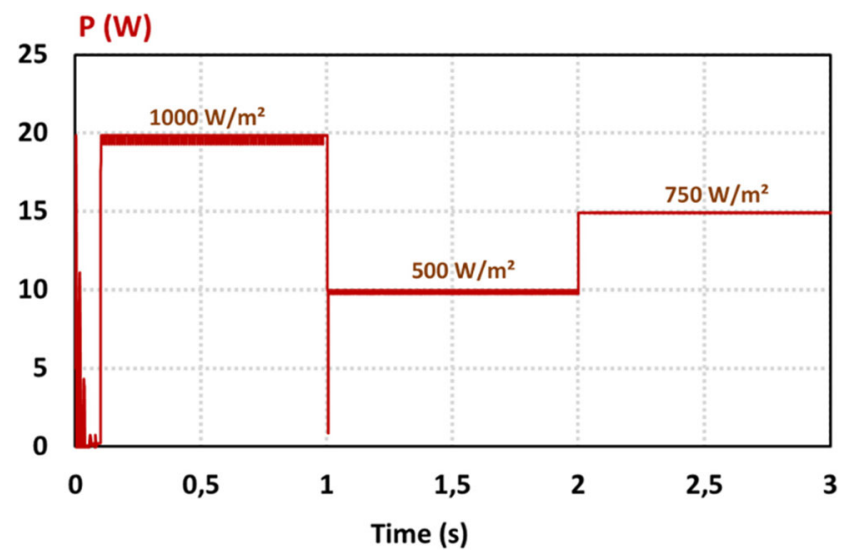

Fig. 16 PV emulator output power with P\&O MPPT algorithm at the difference of the solar irradiance

results that the powers correspond to MPP for the abovementioned temperature conditions are respectively $7 \mathrm{~W}, 5 \mathrm{~W}$ and $4 \mathrm{~W}$. These values are in accordance with those obtained in Fig. 11 which shows the experimental $\mathrm{P}-\mathrm{V}$ curves for different $\mathrm{V}_{\mathrm{oc}}^{\prime}$ values.

Consequently, the experimental results validated that the used PV emulator to be a suitable low-cost solution by the performance average compared to the commercial emulator for PV systems.

\section{The Used Emulator Comparison with Other Emulators}

Table 5 represents a comparison between the used PV emulator and other emulators, based on components, cost, and complexity. The cost of the used emulator is $\$$ 79.99. This price is very low compared with that of other
Fig. 15 Experimental setup of the developed PV system

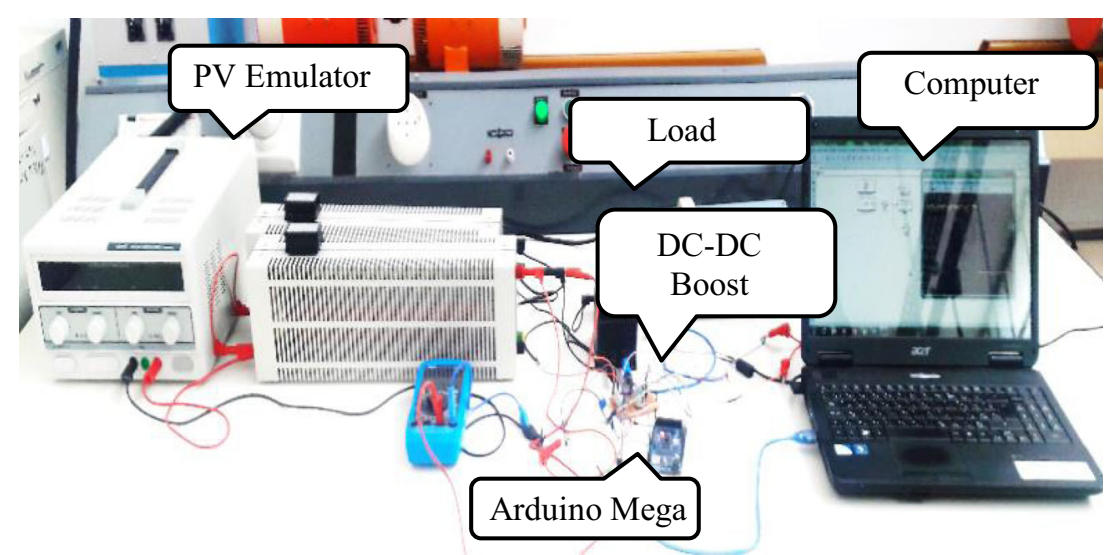




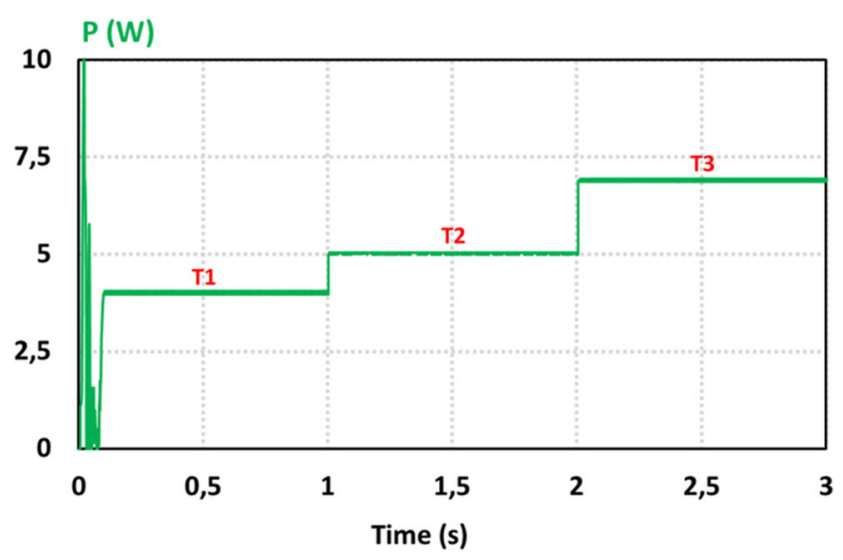

Fig. 17 PV emulator output power with P\&O MPPT algorithm at the difference of temperature levels

emulators, for example, the emulator shown in [16] costs $3500.00 \$$ and the emulator shown in [17] costs $2800.00 \$$. Thus, the used PV emulator is not complex, easy to build and use it in the laboratory.

\section{Conclusion}

The high cost of commercial PV emulators requires finding new solutions for building low-cost system having similar behavior of PV panel. Therefore, this paper describes a low-cost PV emulator by which we replace a PV panel to test the real implementation of MPPT algorithms for PV applications. In this work, the results of experiments test are shown that our PV emulator can provide a P-V curve that it presents a power peak, which can be followed by the MPPT algorithm. In addition, an explication of the PV emulator to simulate a fast variation of the solar irradiance and the temperature in case of PV systems is presented in this work. Moreover, the P\&O MPPT algorithm with a boost DC-DC converter is used in order to validate the functionality of used PV emulator. Finally, the results of the rapid change of irradiance and temperature on the PV emulator confirmed the effectiveness of the PV emulator system and show that our solution has several advantages over existing such as low cost, less complexity, and can provide a simple way for users (researchers, engineers, students, etc.) to test and verify their MPPT algorithms.

As perspective, two prospects for improvement can be done: (i) find a general method to calculate the emulated values of temperature as we did for irradiance. (ii) Improve the present $\mathrm{PV}$ emulator design to be suitable for testing shading conditions.

Nomenclatures $E$, DC supply output voltage [V]; I, PV emulator output current $[\mathrm{A}] ; I_{0}$, the output current of the Boost converter [A]; $I_{\mathrm{mpp}}$, Panel output maximum power point current [A]; G, Solar irradiance level [W/m2]; $P_{\text {load }}$, Load power $[W] ; R_{\text {load }}$, Load resistance $[\Omega] ; R_{\text {Series }}$, Series resistance $[\Omega] ; R_{m p p}$, Resistor value at MPP $[\Omega] ; T$, Temperature $\left[{ }^{\circ} \mathrm{C}\right] ; V, \mathrm{PV}$ emulator output voltage [V]; $V_{\text {mpp }}$, Voltage at MPP [V]; $V_{0}$, Boost output voltage [V]; $V_{o c}^{\prime}, \mathrm{PV}$ emulator open-circuit voltage [V]; $V_{\mathrm{oc}}$, Panel open-circuit voltage [V].

Greek Letters $\alpha$, Duty cycle.

Abbreviations CV, Constant Voltage; DC, Direct Current; INC, Incremental Conductance; MPP, Maximum Power Point; MPPT, Maximum Power Point Tracking; PV, Photovoltaic; P \& O, Perturb and Observe.

Table 5 Comparison between the used emulator and other emulators

\begin{tabular}{|c|c|c|c|}
\hline Work, year & Material used & Cost & Complexity \\
\hline [17], 2012 & $\begin{array}{l}\text { - Programmable DC } \\
\text { Power Supply } \\
\text { (TDK Lambda GEN300-11) } \\
\text { - dSPACE DS1104 }\end{array}$ & $\begin{array}{l}\text { 2800.00\$ } \\
\text { http://www.ebayshopkorea.com/main/viewsitemID=381850543196 }\end{array}$ & High \\
\hline [16], 2014 & $\begin{array}{l}\text { - PV Solar Array } \\
\text { Simulator } \\
\text { (Agilent E4360A) }\end{array}$ & $\begin{array}{l}3500.00 \$ \\
\text { http://www.ebayshopkorea.com/main/viewsitemID=253064937146 }\end{array}$ & High \\
\hline Our work & $\begin{array}{l}\text { - DC regulated } \\
\text { power supply } \\
\text { - variable resistor } \\
320 \mathrm{~W} 100 \Omega\end{array}$ & $\begin{array}{l}64.99 \$ \\
\text { www.ebayshopkorea.com /itm/10A-30V-DC-Power-Supply- } \\
\text { Adjustable-Dual-Digital-/251705177148 } \\
\text { 15.00\$ } \\
\text { http://catalog.efcmd.ma/produit/rheostat-320-w-100/ }\end{array}$ & Less \\
\hline
\end{tabular}




\section{References}

1. Awad A, Bazan P, German R (2016) Optimized operation of PV/T and micro-CHP hybrid power systems. Technol Econ Smart Grids Sustain Energy 1(1):2

2. Ansari B, Simoes MG (2017) Distributed energy management of PV-storage systems for voltage rise mitigation. Technol Econ Smart Grids Sustain Energy 2(1):15

3. Kalogirou SA (2013) Solar energy engineering: processes and systems. Academic Press, New York

4. Singh GK (2013) Solar power generation by PV (photovoltaic) technology: a review. Energy 53:1-13

5. Femia N, Petrone G, Spagnuolo G, Vitelli M (2005) Optimization of perturb and observe maximum power point tracking method. IEEE Trans Power Electron 20(4):963-973

6. Abdelsalam AK, Massoud AM, Ahmed S, Enjeti PN (2011) High-performance adaptive perturb and observe MPPT technique for photovoltaic-based microgrids. IEEE Trans Power Electron 26(4):1010-1021

7. Elgendy MA, Zahawi B, Atkinson DJ (2013) Assessment of the incremental conductance maximum power point tracking algorithm. IEEE Trans Sustain Energy 4(1):108-117

8. Motahhir S, El Ghzizal A, Sebti S, Derouich A (2018) Modeling of photovoltaic system with modified incremental conductance algorithm for fast changes of irradiance. Int $J$ Photoenergy 2018:1-13

9. Motahhir S, El Ghzizal A, Sebti S, Derouich A (2017) MIL and SIL and PIL tests for MPPT algorithm. Cogent Eng 4(1): 1378475

10. Ahmad J (2010) A fractional open circuit voltage based maximum power point tracker for photovoltaic arrays. In: 2010 2nd international conference on software technology and engineering (ICSTE), vol 1, pp V1-247

11. Kottas TL, Boutalis YS, Karlis AD (2006) New maximum power point tracker for PV arrays using fuzzy controller in close cooperation with fuzzy cognitive networks. IEEE Trans Energy Convers 21(3):793-803

12. Rizzo SA, Scelba G (2015) ANN based MPPT method for rapidly variable shading conditions. Appl Energy 145:124-132
13. Elbreki AM et al (2016) The role of climatic-design-operational parameters on combined PV/T collector performance: a critical review. Renew Sustain Energy Rev 57:602-647

14. Xiao W, Dunford WG (2004) Evaluating maximum power point tracking performance by using artificial lights. In: 30th annual conference of IEEE industrial electronics society, 2004. IECON 2004, vol 3, pp 2883-2887

15. Xiao W, Dunford WG (2004) A modified adaptive hill climbing MPPT method for photovoltaic power systems. In: 2004 IEEE 35 th annual power electronics specialists conference (IEEE Cat. No.04CH37551), vol 3, pp 1957-1963

16. Tey KS, Mekhilef S (2014) Modified incremental conductance MPPT algorithm to mitigate inaccurate responses under fastchanging solar irradiation level. Sol Energy 101:333-342

17. Kadri R, Andrei H, Gaubert J-P, Ivanovici T, Champenois G, Andrei P (2012) Modeling of the photovoltaic cell circuit parameters for optimum connection model and real-time emulator with partial shadow conditions. Energy 42(1):57-67

18. Ebrahim AF, Ahmed SMW, Elmasry SE, Mohammed OA (2015) Implementation of a $\mathrm{PV}$ emulator using programmable DC power supply. In: SoutheastCon 2015, pp 1-7

19. Lu DDC, Nguyen QN (2012) A photovoltaic panel emulator using a buck-boost DC/DC converter and a low cost micro-controller. Sol Energy 86(5):1477-1484

20. Zhou Z, Holland PM, Igic P (2014) MPPT algorithm test on a photovoltaic emulating system constructed by a DC power supply and an indoor solar panel. Energy Convers Manag 85:460-469

21. Mukerjee AK, Dasgupta N (2007) DC power supply used as photovoltaic simulator for testing MPPT algorithms. Renew Energy 32(4):587-592

22. Kong CS (1995) A general maximum power transfer theorem. IEEE Trans Educ 38(3):296-298

23. Motahhir S, El Ghzizal A, Sebti S, Derouich A (2015) Une ressource pédagogique pour l'enseignement par simulation: cas des panneaux photovoltaïques. In: Workshop international sur les approches Pédagogiques \& E-Learning

24. El Hammoumi A, Motahhir S, Chalh A, El Ghzizal A, Derouich A (2018) Low-cost virtual instrumentation of PV panel characteristics using Excel and Arduino in comparison with traditional instrumentation. Renew Wind Water Sol 5(1):3 